\title{
Genetic analysis of udder conformation traits derived from automatic milking system recording in dairy cows
}

\author{
M. Poppe, ${ }^{1 *}$ H. A. Mulder, ${ }^{1}$ B. J. Ducro, ${ }^{1}$ and G. de Jong ${ }^{2}$ \\ ${ }^{1}$ Wageningen University \& Research Animal Breeding and Genomics, PO Box 338, 6700 AH Wageningen, the Netherlands \\ ${ }^{2}$ CRV BV, Wassenaarweg 20, 6843 NW Arnhem, the Netherlands
}

\section{ABSTRACT}

Cartesian teat coordinates measured by automatic milking systems (AMS) provide new opportunities to record udder conformation traits and to study changes in udder conformation genetically and phenotypically within and between parities. The objective of this study was to estimate heritabilities and repeatabilities of AMS-based udder conformation traits within parities, to estimate genetic correlations between parities for AMS-based udder conformation traits, and to estimate genetic correlations between AMS-based udder conformation traits and classifier-based udder conformation traits, longevity, and udder health. Data from 70 herds, including 12,663 first-parity cows, 10,206 second-parity cows, and 7,627 third-parity cows, were analyzed using univariate and bivariate mixed animal models. Heritabilities of the AMS udder conformation traits were large (0.37-0.67) and genetic correlations between the AMS udder conformation traits and classifier-based traits were strong $(>0.91)$. Repeatabilities within parities were large as well (0.89-0.97), indicating that a single record on udder conformation per lactation reflects udder conformation well. Genetic correlations of AMS udder conformation traits between parities were strong (0.88-1.00) and were stronger than the permanent environmental correlations. This shows that udder conformation changes over parities, but this change is mostly due to nongenetic factors. Based on these results, the current herd classification system, where cows are scored on udder conformation once in first parity, is sufficient. The AMS udder conformation traits as defined in this study have limited value as replacement for classifier-based udder conformation traits because they have smaller genetic correlations with functional traits than classifier-based traits. In summary, udder conformation hardly changes genetically between parities and is highly repeatable within parities. Udder conformation traits based on AMS need fine-tuning before

Received March 28, 2018.

Accepted October 24, 2018.

*Corresponding author: marieke.poppe@wur.nl they can replace classifier-based traits, and AMS teat coordinates probably contain additional information about udder health that is yet to be explored.

Key words: automatic milking system, udder, conformation, dairy cow

\section{INTRODUCTION}

In the Netherlands, udders of dairy cows are scored for conformation by professional classifiers. Cows participating in the Dutch herd classification system are scored for 7 linear udder conformation traits and an overall udder score (CRV, 2016a). Weak to moderate genetic correlations are found with suitability for automatic milking systems (AMS; Carlström et al., 2016b), milk yield (Short and Lawlor, 1992), udder health (Larroque et al., 1999; Rupp and Boichard, 1999; Samoré and Groen, 2006), and longevity (Short and Lawlor, 1992; Vollema et al., 2000; CRV, 2012b). Although the genetic correlations to functional and production traits are not strong, udder conformation is included in the Dutch-Flemish Index (NVI), because farmers consider udder conformation important for functionality and AMS efficiency. Additionally, it increases their job satisfaction (CRV, 2018a).

Udder conformation is scored once per cow in first parity (CRV, 2016a). However, it is unknown how well this reflects the udder conformation later in life. Due to wear and aging, udder conformation might change and the change might be genetic in part as well. It is therefore important to know the genetic correlation with later parities. Moreover, it is unknown if one observation on udder conformation per cow is sufficient. Different cows are scored for conformation at different lactation stages, and at different times since milking, which has an effect on the maturity and amount of milk in the udder. Although the udder conformation traits are corrected for lactation stage in the breeding value estimation, the time since milking is only subjectively taken into account by classifiers. Scoring udder conformation repeatedly on a cow might give a better and more objective reflection of the true udder conformation. 
To study changes of udder conformation within and between parities, repeated observations are required. With AMS, methods for recording udder conformation have become available that provide multiple records a day on cows of all parities. The AMS measure and store the locations of the 4 teats in space during each AMS visit, which can be used to derive several udder conformation traits. The genetic correlations between udder conformation traits recorded by AMS and udder conformation traits scored by classifiers are close to unity (Byskov et al., 2012; Carlström et al., 2016b), indicating that udder conformation recorded by AMS can be used as a proxy for udder conformation scored by classifiers. The AMS teat coordinates thus provide excellent opportunities to study genetically and phenotypically the development of udders within and between lactations.

The aims of this study were to (1) estimate heritabilities and repeatabilities of AMS-based udder conformation traits recorded in parity 1,2 , and $3,(2)$ estimate genetic correlations between parity 1, 2, and 3 for the AMS-based udder conformation traits, (3) estimate genetic correlations between AMS-based udder conformation traits and corresponding traits scored by classifiers, and (4) estimate genetic correlations of both AMS-based and classifier-based udder conformation traits with longevity and udder health.

\section{MATERIALS AND METHODS}

\section{Data}

A dataset containing frequent milking records recorded by Lely AMS (Lely, Maassluis, the Netherlands) from 70 commercial Dutch dairy farms in the period from 2006 to 2016 was provided by CRV (CRV Holding BV, Arnhem, the Netherlands). The original data set contained records of all robot visits $(39,669,758)$ of the 19,997 cows in this period. However, to facilitate computation, only every 20th record was extracted. This resulted in approximately 1 record per week for each cow assuming $\sim 3$ milk visits per day, which was assumed to be sufficient for traits that do not vary a lot over time. This resulted in 1,983,487 milking records of 19,700 cows. All data handling was performed using the statistical programming language $\mathrm{R}(\mathrm{R} \vee 3.2 .2 ; \mathrm{R}$ Project for Statistical Computing, Vienna, Austria). Each milking record contained Cartesian coordinates $(\mathrm{x}, \mathrm{y}, \mathrm{z})$ of each of the 4 teats, indicating the 3-dimensional location of the teat tips. The $\mathrm{z}$ coordinate was a measure of the distance from the teat tip to the floor, the y coordinate was a measure of the position of the teat on the axis parallel to the long side of the robot, and the $\mathrm{x}$ coordinate was a measure of the position of the teat on the axis perpendicular to the long side of the robot. The Cartesian teat coordinates in the AMS data set were used to calculate the udder conformation traits rear teat distance, front teat distance, udder depth, distance between front and rear teats (hereafter, this trait will be referred to as distance front-rear), and udder balance (the difference in depth between front and rear udder). A specification of the udder conformation traits and equations for calculation are given in Table 1. Hereafter, these traits will be referred to as AMS udder conformation traits. To adjust for herd, year of milking, and season of milking, herd-year-season (HYS) classes were made. Four seasons were distinguished: March 21 to June 20, June 21 to September 20, September 21 to December 20, and December 21 to March 20. Cows included in the analysis were required to be registered and to be at least $87.5 \%$ Holstein Friesian. Records of milk visits after $350 \mathrm{~d}$ in lactation were removed. Additionally, records of failed milk visits were removed. One of the possible reasons for a milking to fail was that the location of the teats was recorded incorrectly, for example, because of dirt on the teats or the laser. To answer our objectives, we needed accurate measurements of the teat coordinates, which is why we removed failed milk visits from the data. Moreover, records with a milk yield of 0 , records with a $\mathrm{z}$ coordinate of 0 , and records containing wrong calving dates were removed. To detect remaining incorrect records of the AMS udder conformation traits, a fixed model was fitted using ASReml 4.1 (Gilmour et al., 2015) for the traits udder depth, front teat distance, rear teat distance, and distance front-rear:

$$
\text { Udder trait }=\mu+\text { parity }+ \text { animal }+ \text { DIM }+ \text { DIM }^{2}+\text { e, }
$$

where $\mu$ was the intercept, parity was the parity of the analyzed animal, animal was the analyzed animal, DIM was the number of days in milk, and e was the error term. The model was selected such that the curve would follow the actual lactation curve sufficiently upon visual inspection, while keeping the model as simple as possible. Records with a residual larger than 4 times the residual standard deviation were removed. The threshold of 4 times the residual standard deviation was decided to be severe enough to detect records unlikely to be correct in relation to their cow-specific curves upon visual inspection. After removal of outliers and faulty records, the data set contained 1,535,290 records on 16,672 animals in 14 lactations from 70 farms, sired by 1,913 sires. Table 2 shows the number of final records and cows for parity 1,2 , and 3 , which were used for analysis. 
Table 1. Description and calculation of the udder conformation traits derived from the Cartesian automatic milking system teat coordinates

\begin{tabular}{|c|c|c|}
\hline $\begin{array}{l}\text { Udder conformation } \\
\text { trait }\end{array}$ & Description & Calculation $^{1}$ \\
\hline Udder depth & Average distance of teat ends to the floor in $\mathrm{mm}$ & $\frac{\mathrm{z}_{\mathrm{lf}}+z_{\mathrm{rf}}+\mathrm{z}_{\mathrm{lr}}+\mathrm{z}_{\mathrm{rr}}}{4}$ \\
\hline Front teat distance & Distance between left and right front teat ends in $\mathrm{mm}$ & $x_{\mathrm{lf}}-\mathrm{x}_{\mathrm{rf}}$ \\
\hline Rear teat distance & Distance between left and right rear teat ends in $\mathrm{mm}$ & $\mathrm{x}_{\mathrm{lr}}-\mathrm{x}_{\mathrm{rr}}$ \\
\hline Distance front-rear & Average distance between the front and rear teat ends in $\mathrm{mm}$ & $\frac{\mathrm{y}_{\mathrm{lr}}+\mathrm{y}_{\mathrm{rr}}}{2}-\frac{\mathrm{y}_{\mathrm{lf}}+\mathrm{y}_{\mathrm{rf}}}{2}$ \\
\hline
\end{tabular}

${ }^{1}$ lf $=$ left front teat; $\mathrm{rf}=$ right front teat; $\mathrm{lr}=$ left rear teat; $\mathrm{rr}=$ right rear teat; $\mathrm{z}=\mathrm{z}$-coordinate; $\mathrm{y}=\mathrm{y}$-coordinate; $\mathrm{x}=\mathrm{x}$-coordinate.

Besides the AMS data set, a data set was available containing classification scores on all linear conformation traits (CRV, 2016a) of 10,532 first parity cows from 158 farms routinely classified between 1996 and 2016 and sired by 1,401 sires. Part of the cows in this data set were also present in the AMS data set. Classification scores ranged from 1 to 9 and were scored by 28 professional classifiers. The number of days between calving and classification ranged from 3 to $469 \mathrm{~d}$ and the age at first calving ranged from 20 to 34 mo. We made HYS of classification classes. Interest was only in the traits front teat placement, rear teat placement, and udder depth. The number of cows having a record in both the classification data set and the AMS data set was 7,179 , whereas 5,484 cows had only AMS conformation trait records and 3,344 cows had only a classification score. A complete pedigree was available for all cows in both data sets. To reduce computing time, a reduced pedigree data set was generated including 5 generations of ancestors.

\section{Statistical Analysis}

Repeatedly Recorded AMS Udder Conformation Traits in Different Parities. Heritabilities, repeatabilities, and breeding values were estimated for the AMS udder conformation traits. This was performed separately for parity 1,2, and 3, each parity containing multiple records per cow. The analyses were performed using the following univariate repeatability model:

$$
\mathbf{y}=\mathbf{X b}+\mathbf{Z}_{1} \mathbf{a}+\mathbf{Z}_{2} \mathbf{p}+\mathbf{e},
$$

where $\mathbf{y}$ was a vector containing repeated phenotypic records for the analyzed trait in either parity 1,2 , or 3 (all normally distributed upon visual inspection); $\mathbf{b}$ was a vector containing the fixed effects for the analyzed trait in either parity 1,2 , or 3 , which were DIM, DIM ${ }^{2}$, age at calving in months, month of calving, and HYS of milk record; a was a vector containing the additive genetic effects of the cows in $\mathbf{y}$ for the analyzed trait in either parity 1,2 , or $3, \mathbf{a} \sim N\left(\mathbf{0}, \mathbf{A} \sigma_{a}^{2}\right)$, where $\mathbf{A}$ is the additive genetic relationship matrix and $\sigma_{a}^{2}$ is the additive genetic variance; $\mathbf{p}$ was a vector containing the permanent environmental effects of the cows in $\mathbf{y}$ for the analyzed trait in either parity 1,2 , or $3, \mathbf{p} \sim N\left(\mathbf{0}, \mathbf{I} \sigma_{p e}^{2}\right)$, where $\mathbf{I}$ is an incidence matrix and $\sigma_{p e}^{2}$ is the permanent environmental variance; e was a vector containing the residuals, $\mathbf{e} \sim N\left(\mathbf{0}, \mathbf{I} \sigma_{e}^{2}\right)$, where $\sigma_{e}^{2}$ is the residual variance. $\mathbf{X}, \mathbf{Z}_{1}$, and $\mathbf{Z}_{2}$ were incidence matrices linking the phenotypic records of the analyzed trait to the fixed effects, additive genetic effects, and permanent environmental effects, respectively. Estimation of all variance components was performed using ASReml 4.1 (Gilmour et al., 2015).

For each AMS udder conformation trait, genetic correlations between the records in parity 1 and 2 , between the records in parity 1 and 3 , and between the records in parity 2 and 3 , were estimated. Trivariate analyses including an AMS udder conformation trait in 3 different parities did not converge, likely due to the large genetic correlations between parities. Therefore, the genetic correlations were estimated using the following bivariate repeatability model:

$\left[\begin{array}{l}\mathbf{y}_{1} \\ \mathbf{y}_{2}\end{array}\right]=\left[\begin{array}{cc}\mathbf{X}_{1} & 0 \\ 0 & \mathbf{X}_{2}\end{array}\right]\left[\begin{array}{l}\mathbf{b}_{1} \\ \mathbf{b}_{2}\end{array}\right]+\left[\begin{array}{cc}\mathbf{z}_{\mathbf{a} 1} & 0 \\ 0 & \mathbf{Z}_{\mathbf{a} 2}\end{array}\right]\left[\begin{array}{c}\mathbf{a}_{1} \\ \mathbf{a}_{2}\end{array}\right]+\left[\begin{array}{cc}\mathbf{z}_{\mathbf{p} 1} & 0 \\ 0 & \mathbf{Z}_{\mathbf{p} 2}\end{array}\right]\left[\begin{array}{l}\mathbf{p}_{1} \\ \mathbf{p}_{2}\end{array}\right]+\left[\begin{array}{l}\mathbf{e}_{1} \\ \mathbf{e}_{2}\end{array}\right]$,

where $\mathbf{y}_{1}$ was a vector containing repeated records of a particular AMS conformation trait in parity 1 or 2 , and $\mathbf{y}_{2}$ was a vector containing repeated records of the same

Table 2. Number of analyzed automatic milking system-based udder conformation trait records and cows per parity

\begin{tabular}{lrr}
\hline Parity & Records & Cows \\
\hline 1 & 479,761 & 12,663 \\
2 & 398,933 & 10,206 \\
3 & 292,242 & 7,627 \\
\hline
\end{tabular}


trait in parity 2 or $3 ; \mathbf{b}_{1}$ and $\mathbf{b}_{2}$ were vectors containing the fixed effects for the trait in the 2 parities, which were the same as in the univariate analysis; $\mathbf{a}_{1}$ and $\mathbf{a}_{2}$ were vectors containing the additive genetic effects of the cows in $\mathbf{y}_{1}$ and $\mathbf{y}_{2}$ for the trait in the 2 parities; $\mathbf{p}_{1}$ and $\mathbf{p}_{2}$ were vectors containing the permanent environmental effects of the cows in $\mathbf{y}_{1}$ and $\mathbf{y}_{2}$ for the trait in the 2 parities; and $\mathbf{e}_{1}$ and $\mathbf{e}_{2}$ were vectors containing the residuals. The following assumptions were made about the additive genetic effects, the permanent environmental effects, and the residuals:

$$
\begin{aligned}
& {\left[\begin{array}{l}
\mathbf{a}_{1} \\
\mathbf{a}_{2}
\end{array}\right] \sim N\left(\left(\begin{array}{l}
0 \\
0
\end{array}\right), \mathbf{A} \otimes\left(\begin{array}{cc}
\sigma_{a_{1}}^{2} & \sigma_{a_{1} a_{2}} \\
\sigma_{a_{1} a_{2}} & \sigma_{a_{2}}^{2}
\end{array}\right)\right),} \\
& {\left[\begin{array}{l}
\mathbf{p}_{1} \\
\mathbf{p}_{2}
\end{array}\right] \sim N\left(\left(\begin{array}{l}
0 \\
0
\end{array}\right), \mathbf{I} \otimes\left(\begin{array}{cc}
\sigma_{p e_{1}}^{2} & \sigma_{p e_{1} p e_{2}} \\
\sigma_{p e_{1} p e_{2}} & \sigma_{p e_{2}}^{2}
\end{array}\right)\right), \text { and }} \\
& {\left[\begin{array}{l}
\mathbf{e}_{1} \\
\mathbf{e}_{2}
\end{array}\right] \sim N\left(\left(\begin{array}{l}
0 \\
0
\end{array}\right), \mathbf{I} \otimes\left(\begin{array}{cc}
\sigma_{e_{1}}^{2} & 0 \\
0 & \sigma_{e_{2}}^{2}
\end{array}\right)\right),}
\end{aligned}
$$

where $\sigma_{a_{i}}^{2}$ is the additive genetic variance for the trait in one or the other parity, $\sigma_{a_{1} a_{2}}$ is the additive genetic covariance between the trait in the 2 parities, $\sigma_{p e_{i}}^{2}$ is the permanent environmental variance for the trait in one or the other parity, $\sigma_{p e_{1} p e_{2}}$ is the permanent environmental covariance between the trait in the 2 parities, and $\sigma_{e_{i}}^{2}$ is the residual variance for the trait in one or the other parity. $\mathbf{X}_{1}$ and $\mathbf{X}_{2}$, as well as $\mathbf{Z}_{\mathrm{a} 1}$ and $\mathbf{Z}_{\mathrm{a} 2}$, and $\mathbf{Z}_{\mathbf{p} 1}$ and $\mathbf{Z}_{\mathrm{p} 2}$ were incidence matrices linking the phenotypic records of the trait in the 2 analyzed parities to the fixed effects, additive genetic effects, and permanent environmental effects, respectively. Data of cows that moved to one of the herds in our data set from a herd outside the data set in parity 2 or 3 were excluded from the bivariate analyses. Thus, cows with records in parity 2 also had records in parity 1 and cows with records in parity 3 also had records in parity 1 and 2 . Cows that moved between herds within the data set were not excluded from the analyses.

Heritabilities and repeatabilities $(t)$ for the AMS udder conformation traits in parity 1,2 , and 3 were calculated from the variance components as

$$
\begin{aligned}
h^{2} & =\frac{\sigma_{a}^{2}}{\sigma_{a}^{2}+\sigma_{p e}^{2}+\sigma_{e}^{2}}, \\
t & =\frac{\sigma_{a}^{2}+\sigma_{p e}^{2}}{\sigma_{a}^{2}+\sigma_{p e}^{2}+\sigma_{e}^{2}} .
\end{aligned}
$$

Genetic correlations $\left(\mathrm{r}_{\mathrm{g}}\right)$ of AMS udder conformation traits between parities were calculated from the variance components as

$$
r_{g}=\frac{\sigma_{a_{1} a_{2}}}{\sqrt{\sigma_{a_{1}}^{2} \sigma_{a_{2}}^{2}}} .
$$

Genetic Correlations Between AMS Conformation Traits and Udder Conformation Scored by Classifiers. For the udder conformation traits scored by classifiers, heritabilities were estimated using the following univariate model:

$$
\mathbf{y}=\mathbf{X b}+\mathbf{Z a}+\mathbf{e},
$$

where $\mathbf{y}$ was a vector containing the phenotypic records for the analyzed trait, which was either udder depth, or front or rear teat placement (all normally distributed upon visual inspection); $\mathbf{b}$ was a vector containing the fixed effects for the analyzed trait, which were classifier, age at calving in months, month of calving, time between calving and classification in weeks, and HYS of classification; a was a vector containing the additive genetic effects of the cows in $\mathbf{y}$ for the analyzed trait, $\mathbf{a} \sim N\left(\mathbf{0}, \mathbf{A} \sigma_{a}^{2}\right)$; and $\mathbf{e}$ was a vector containing the residuals, $\mathbf{e} \sim N\left(\mathbf{0}, \mathbf{I} \sigma_{e}^{2}\right)$. $\mathbf{X}$ and $\mathbf{Z}$ were incidence matrices linking the phenotypic records of the analyzed trait to the fixed effects and additive genetic effects, respectively.

Genetic correlations between the AMS udder conformation traits and corresponding traits scored by classifiers were estimated using the following bivariate model, with lactation averages for the AMS udder conformation traits for computational ease and single observations on the classified udder conformation traits:

$$
\left[\begin{array}{l}
\mathbf{y}_{1} \\
\mathbf{y}_{2}
\end{array}\right]=\left[\begin{array}{cc}
\mathbf{X}_{1} & 0 \\
0 & \mathbf{X}_{2}
\end{array}\right]\left[\begin{array}{l}
\mathbf{b}_{1} \\
\mathbf{b}_{2}
\end{array}\right]+\left[\begin{array}{cc}
\mathbf{z}_{\mathbf{a} 1} & 0 \\
0 & \mathbf{Z}_{\mathbf{a}_{2}}
\end{array}\right]\left[\begin{array}{l}
\mathbf{a}_{1} \\
\mathbf{a}_{2}
\end{array}\right]+\left[\begin{array}{l}
\mathbf{e}_{1} \\
\mathbf{e}_{2}
\end{array}\right],
$$

where $\mathbf{y}_{1}$ was a vector containing lactation averages for a particular AMS udder conformation trait in first lactation and $\mathbf{y}_{2}$ was a vector containing classification scores for the corresponding classified trait; $\mathbf{b}_{1}$ and $\mathbf{b}_{2}$ were vectors containing the fixed effects for the 2 corresponding traits, which were age at calving in months, month of calving, and HYS of calving for the AMS udder conformation traits, and the same fixed effects as in the univariate analysis for the classified udder conformation traits; $\mathbf{a}_{1}$ and $\mathbf{a}_{2}$ were vectors containing the additive genetic effects of the cows in $\mathbf{y}_{1}$ and $\mathbf{y}_{2}$ for the 2 corresponding traits; and $\mathbf{e}_{1}$ and $\mathbf{e}_{2}$ were vectors 
containing the residuals. The following assumptions were made about the additive genetic effects and the residuals:

$$
\begin{aligned}
& {\left[\begin{array}{l}
\mathbf{a}_{1} \\
\mathbf{a}_{2}
\end{array}\right] \sim N\left[\left(\begin{array}{l}
0 \\
0
\end{array}\right), \mathbf{A} \otimes\left(\begin{array}{cc}
\sigma_{a_{1}}^{2} & \sigma_{a_{1} a_{2}} \\
\sigma_{a_{1} a_{2}} & \sigma_{a_{2}}^{2} \\
a_{2}
\end{array}\right]\right),} \\
& {\left[\begin{array}{l}
\mathbf{e}_{1} \\
\mathbf{e}_{2}
\end{array}\right] \sim N\left[\left(\begin{array}{l}
0 \\
0
\end{array}\right), \mathbf{I} \otimes\left(\begin{array}{cc}
\sigma_{e_{1}}^{2} & \sigma_{e_{1} e_{2}} \\
\sigma_{e_{1} e_{2}} & \sigma_{e_{2}}^{2}
\end{array}\right)\right] .}
\end{aligned}
$$

Heritabilities of the udder conformation traits scored by classifiers and genetic correlations between the udder conformation traits scored by classifiers and the AMS udder conformation traits were calculated from the variance components.

Genetic Correlations Between Udder Conformation Traits and Functional Traits. To obtain a fast insight in the genetic correlation between udder conformation traits (both AMS and classifier traits) and functional traits, without the use of complex models, it was decided to calculate approximate genetic correlations using the Calo method (Calo et al., 1973). Such a correlation is a Pearson correlation between breeding values, corrected for their reliabilities. See Elgersma et al. (2018) for an explanation of this method. Breeding values were available for the functional traits longevity (CRV, 2012b), clinical mastitis, subclinical mastitis, SCS, and the udder health index (CRV, 2016b). Breeding values of 8,431 sires from routine evaluations for these functional traits were provided by CRV. Reliabilities of the breeding values for longevity ranged from 4 to $99 \%$ and reliabilities of the breeding values for the udder health traits ranged from 21 to $99 \%$. For the AMS udder conformation traits and udder conformation traits scored by classifiers, breeding values were taken from the univariate analyses performed in this study on first-parity records. The reliability of the breeding values included in the calculation of the approximated genetic correlations was required to be at least $70 \%$ to avoid upward bias of the correlations. Between 156 and 241 sires had sufficiently reliable breeding values for both longevity or udder health traits and the AMS udder conformation traits. The number of sires with sufficiently reliable breeding values for the udder conformation traits scored by classifiers ranged between 126 and 136.

Selection Index Calculations to Quantify Benefit of AMS Udder Conformation Traits. Selection index calculations were performed for the trait udder depth to illustrate the benefit of having observations on udder conformation recorded by AMS compared with observations on udder conformation scored by classi- fiers. In SelAction v2.2 (Rutten et al., 2002), a genomic breeding scheme was simulated. Selection was on ud-

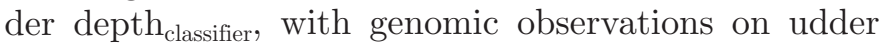
depth $_{\text {classifier }}$ and udder depth $\mathrm{AmS}_{\text {as }}$ index sources. The reference population consisted of either 15,000 cows with phenotypes or 5,000 bulls with each 770 daughters with phenotypes for udder depth AMS $_{\text {( }}$ (770 is the average number of daughters of the Holstein and Red Holstein Dutch proven sire lists of CRV multiplied by the percentage of Dutch farms milking with an AMS (CRV, 2018b; Stichting Kwaliteitszorg Onderhoud Melkinstallaties, 2018). The number of cows or bulls in the reference population with information on udder depth classifier $_{\text {. }}$ varied from 0 to 50,000. Each bull in the reference population was assumed to have 1,900 daughters with a record for udder depth classifier $_{\text {(the average number of }}$ daughters in the conformation proofs of the Dutch bulls on the Holstein and Red Holstein proven sire lists of CRV, 2018b). To mimic that the selection pressure on udder conformation is not high because of a balanced breeding goal, we ignored the Bulmer effect by setting the proportion of selected parents to 1 . The phenotypic variances and heritabilities of udder depth $\mathrm{AmS}_{\mathrm{A}}$ and udder depth $\mathrm{c}_{\text {classifier }}$, and the genetic and phenotypic correlations between them were taken from the bivariate analysis of udder depth $\mathrm{AMS}_{\mathrm{A}}$ and udder depth $\mathrm{c}_{\text {classifier }}$ performed in this study. The genetic and phenotypic correlations between the 2 udder depth traits and their genomic breeding values were calculated using their heritabilities and the accuracies of the genomic breeding values (see Dekkers, 2007; Daetwyler et al., 2008). In case of a bull reference population, the accuracies of the genomic breeding values were calculated using the reliability of the breeding values of the bulls in the reference population instead of the heritability of the trait. The effective number of chromosomal segments was assumed to be 1,200 considering an effective population size of 500 (Lee et al., 2017). The accuracy of an

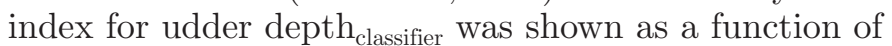
the size of the reference population, where the reference population consisted of a varying number of cows or bulls with information on udder depth classifier $_{\text {and either }}$ 15,000 cows $/ 5,000$ bulls or no animals with information on udder $\operatorname{depth}_{\mathrm{AMS}}$.

\section{RESULTS}

\section{Descriptive Statistics}

Table 3 shows the descriptive statistics of the AMS udder conformation traits in parity 1,2 , and 3 , the udder conformation traits scored by classifiers, and the sire breeding values for the functional traits. It was observed that udders became deeper and distance front- 
rear increased over lactations. The means of rear teat distance, front teat distance, and udder balance did not change much with parity, and their standard deviations were large compared with their means. The mean of udder balance was positive for all 3 parities, which indicates that on average rear udders were further away from the floor than front udders for the Holstein cows in the AMS data set. For all 3 udder conformation traits scored by classifiers, the mean was between 4.97 and 5.39 , with a standard deviation between 1.41 and 1.70. The average of the breeding values for all functional traits except longevity ranged between 99.18 and 100.50 with a standard deviation between 4.54 and 4.83 . The average breeding value for longevity was $-164.83 \mathrm{~d}$ with a standard deviation of $309.57 \mathrm{~d}$.

\section{AMS Udder Conformation Traits in Different Parities}

The heritabilities of AMS conformation traits ranged between 0.40 and 0.69 in parity 1 , between 0.41 and 0.65 in parity 2 , and between 0.37 and 0.67 in parity 3 (Table 4). Udder depth showed the largest heritabilities and udder balance the smallest. The repeatabilities of all traits ranged between 0.89 and 0.97 in all parities, which indicates that measurement error was small and traits remained consistent throughout each lactation. For most traits, the heritability decreased from parity 1 to 2 and from parity 1 to 3 , whereas the additive genetic variance, permanent environmental variance, and repeatability in general increased (Table 4).

For all traits, the genetic correlation between parity 1 and 2 was between 0.94 and 0.99 (Table 5). For all traits, the genetic correlation between parity 2 and 3 was between 0.99 and 1.00, and for front teat distance and udder balance this genetic correlation was not significantly different from unity. The genetic correlation between parity 1 and 3 was between 0.88 and 0.97 .

Permanent environmental correlations for the different traits ranged from 0.71 to 0.82 between parity 1 and 2 , from 0.78 to 0.88 between parity 2 and 3 , and from 0.58 to 0.74 between parity 1 and 3. Phenotypic correlations ranged from 0.74 to 0.91 between parity 1 and 2 , from 0.81 to 0.93 between parity 2 and 3 , and from 0.65 to 0.87 between parity 1 and 3 . In summary, genetic correlations of AMS udder conformation traits between parities were mostly close to unity, and were larger than both permanent environmental and phenotypic correlations, showing that traits change phenotypically more than genetically.

\section{Genetic Correlations with Udder Conformation Traits Scored by Classifiers}

The absolute values of the genetic correlations between the AMS udder conformation traits and corresponding traits scored by classifiers ranged between

Table 3. Descriptive statistics of the automatic milking system-based (AMS) udder conformation traits in parity 1, 2, and 3, the udder conformation traits scored by classifiers in parity 1 , and the breeding values for the functional traits of the sires used for the estimation of genetic correlations between AMS traits and functional traits

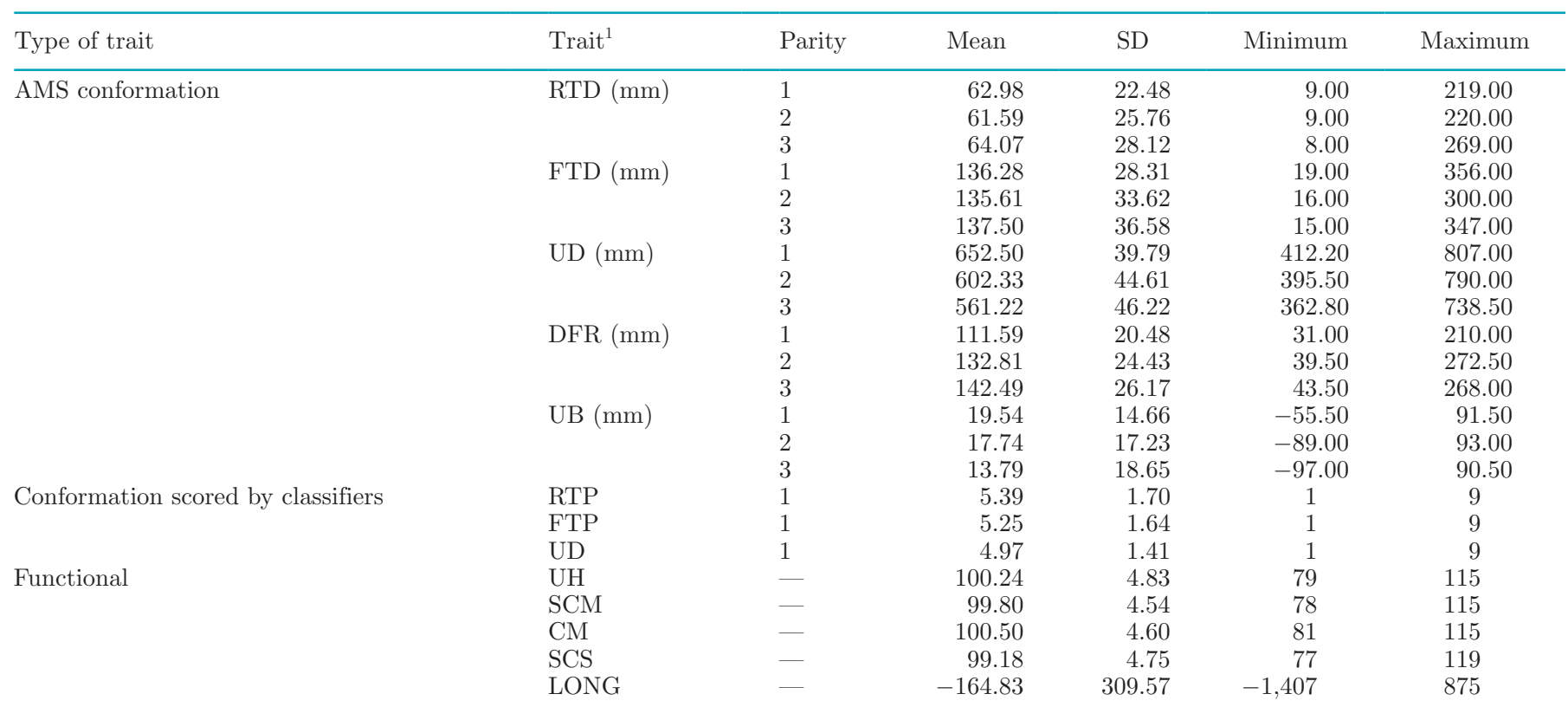

${ }^{1} \mathrm{RTD}=$ rear teat distance $\mathrm{FTD}=$ front teat distance $\mathrm{UD}=$ udder depth; $\mathrm{DFR}=$ distance front-rear; UB $=$ udder balance; RTP $=$ rear teat placement; FTP $=$ front teat placement; $\mathrm{UH}=$ udder health; $\mathrm{SCM}=$ subclinical mastitis; $\mathrm{CM}=$ clinical mastitis; LONG $=$ longevity. 
Table 4. Variance components $\left(\sigma_{a}^{2}=\right.$ additive genetic variance; $\sigma_{p e}^{2}=$ permanent environmental variance; $\sigma_{e}^{2}=$ error variance; $\sigma_{p}^{2}=$ phenotypic variance), heritabilities $\left(\mathrm{h}^{2}\right)$, and repeatabilities $(t)$ from the univariate analysis of the automatic milking system-based udder conformation traits in parity 1, 2, and 3 (SE in parentheses)

\begin{tabular}{|c|c|c|c|c|c|c|c|}
\hline $\begin{array}{l}\text { Conformation } \\
\text { trait }^{1}\end{array}$ & Parity & $\sigma_{a}^{2}$ & $\sigma_{p e}^{2}$ & $\sigma_{e}^{2}$ & $\sigma_{p}^{2}$ & $h^{2}$ & $t$ \\
\hline \multirow{2}{*}{$\mathrm{RTD}(\mathrm{mm})$} & 1 & $231.75(12.37)$ & $202.38(8.24)$ & $55.56(0.12)$ & $489.69(6.97)$ & $0.47(0.02)$ & $0.89(0.00)$ \\
\hline & 2 & $301.31(19.63)$ & $308.48(13.61)$ & $50.63(0.12)$ & $660.42(10.69)$ & $0.46(0.02)$ & $0.92(0.00)$ \\
\hline \multirow[t]{3}{*}{ FTD $(\mathrm{mm})$} & 1 & $483.06(20.99)$ & $254.18(12.94)$ & $61.28(0.13)$ & $798.52(12.07)$ & $0.60(0.02)$ & $0.92(0.00)$ \\
\hline & 2 & $650.27(33.76)$ & $391.26(21.68)$ & $71.49(0.16)$ & $1,113.0(18.74)$ & $0.58(0.02)$ & $0.94(0.00)$ \\
\hline & 3 & $717.97(48.97)$ & $559.30(33.49)$ & $77.12(0.21)$ & $1,354.40(26.01)$ & $0.53(0.03)$ & $0.94(0.00)$ \\
\hline UD (mm) & 1 & $1,123.44(44.53)$ & $453.17(26.36)$ & $60.82(0.13)$ & $1,637.40(25.93)$ & $0.69(0.02)$ & $0.96(0.00)$ \\
\hline \multirow[t]{3}{*}{$\mathrm{DFR}(\mathrm{mm})$} & 1 & $270.78(11.74)$ & $144.54(7.24)$ & $27.91(0.06)$ & $443.24(6.78)$ & $0.61(0.02)$ & $0.94(0.00)$ \\
\hline & 2 & $316.28(16.99)$ & $212.26(11.08)$ & $32.00(0.07)$ & $560.54(9.43)$ & $0.56(0.02)$ & $0.94(0.00)$ \\
\hline & 3 & $375.83(23.00)$ & $214.67(15.10)$ & $32.39(0.09)$ & $622.89(12.25)$ & $0.60(0.03)$ & $0.95(0.00)$ \\
\hline \multirow[t]{3}{*}{$\mathrm{UB}(\mathrm{mm})$} & 1 & $82.72(5.14)$ & $102.07(3.62)$ & $19.90(0.04)$ & $204.69(2.89)$ & $0.40(0.02)$ & $0.90(0.00)$ \\
\hline & 2 & $122.74(8.58)$ & $150.64(6.12)$ & $23.31(0.05)$ & $296.70(4.71)$ & $0.41(0.02)$ & $0.92(0.00)$ \\
\hline & 3 & $131.79(11.75)$ & $190.93(8.77)$ & $23.16(0.06)$ & $345.88(6.29)$ & $0.38(0.03)$ & $0.93(0.00)$ \\
\hline
\end{tabular}

${ }^{1} \mathrm{RTD}=$ rear teat distance; FTD $=$ front teat distance; UD = udder depth; DFR = distance front-rear; UB = udder balance.

0.91 and 0.97 (Table 6). The genetic correlations between the teat placement traits had a negative sign, because teat placement was measured from wide to narrow, whereas distance between teats was measured from narrow to wide. The heritabilities of the classification traits ranged between 0.45 and 0.49 (Table 6), and were smaller than the heritabilities of the corresponding AMS udder conformation traits. In summary, AMS udder conformation traits had a strong genetic correlation with udder conformation traits scored by classifiers, and had a larger heritability than the classifier traits.

\section{Genetic Correlations with Functional Traits}

Table 7 shows that longevity had weak approximated genetic correlations with the AMS udder conformation traits, ranging between -0.17 and 0.18 . The udder health traits showed moderate approximated genetic correlations with the AMS traits udder depth (0.30 to $0.35)$ and distance front-rear $(-0.20$ to -0.27$)$. The genetic correlations of the udder health traits with the remaining AMS udder conformation traits were weak $(-0.15$ to 0.15$)$. The genetic correlation between udder depth classifier $_{\text {and longevity (0.40) was twice as large }}$ as the genetic correlation between udder depth $\mathrm{AMS}_{\mathrm{An}}$ and

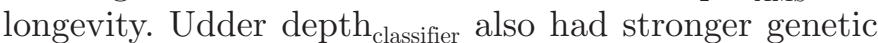
correlations with the udder health traits (0.38 to 0.46 ) than udder depth $\mathrm{h}_{\text {Ams }}$. Due to difference in definition of the teat placement traits (scoring from wide to narrow versus narrow to wide), the signs of the genetic correlations with the functional traits were opposite for these traits, and absolute values will be considered. Front teat placement classifier $_{\text {had stronger genetic correlations }}$ with the udder health traits (0.21 to 0.25$)$ than front teat distance $_{\mathrm{Ams}}(0.03$ to 0.07$)$. The genetic correlation with longevity was comparable between front teat placement $_{\text {classifier }}$ and front teat distance ${ }_{\mathrm{AMS}}$. The genetic correlations between rear teat placement classifier $_{\text {and }}$ the functional traits were comparable to the genetic correlations between rear teat distance $_{\mathrm{AMS}}$ and the functional traits. In summary, genetic correlations between the udder conformation traits and the functional traits were weak to moderate, and in general the udder conformation traits scored by classifiers had stronger genetic correlations with the functional traits than the AMS udder conformation traits.

\section{Selection Index Calculations: The Benefit of AMS Udder Conformation Traits}

The selection index calculations showed the increase

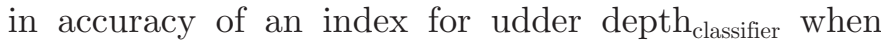
15,000 cows or 5,000 bulls with information on udder depth $_{\text {AMS }}$ were added to a reference population already containing varying numbers of cows or bulls with information on udder depth $\mathrm{h}_{\text {classifier }}$. In case of a cow reference population (Figure 1A), the addition of 15,000 cows with a phenotype for udder depth $\mathrm{AMS}_{\mathrm{A} S}$ notably increased the accuracy of the genomic index for udder depth classifier $_{\text {in }}$ when there were 0 to $\sim 10,000$ cows with phenotypes for

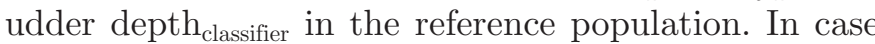
of a bull reference population (Figure 1B), the addition of 5,000 bulls with daughters with phenotypes for ud-

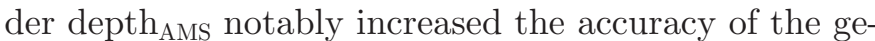
nomic index for udder depth $\mathrm{c}_{\text {classifier }}$ when there were 0 to $\sim 5,000$ bulls with daughter information on udder dep$t_{\text {classifier }}$ in the reference population. If there were more than $\sim 10,000$ cows or $\sim 5,000$ bulls with phenotypes or 
Table 6. Heritabilities of front teat placement (FTP), rear teat placement (RTP), and udder depth (UD) scored by classifiers (parity 1 , univariate analysis), and the genetic correlation $\left(r_{g}\right)$ of these traits with the corresponding automatic milking system-based (AMS) conformation traits in parity 1 (front teat distance, rear teat distance, and udder depth, respectively), with SE in parentheses

\begin{tabular}{lcc}
\hline $\begin{array}{l}\text { Conformation } \\
\text { trait }\end{array}$ & \multicolumn{1}{c}{$\mathrm{h}^{2}$} & $r_{g}$ \\
\hline FTP & $0.46(0.02)$ & $-0.96(0.01)^{1}$ \\
RTP & $0.45(0.03)$ & $-0.97(0.01)^{1}$ \\
UD & $0.49(0.03)$ & $0.91(0.02)$ \\
\hline
\end{tabular}

${ }^{1}$ Negative values because front teat placement and rear teat placement are measured from wide to small, whereas front teat distance and rear teat distance derived from AMS records are measured from small to wide.

daughters with phenotypes for udder depth classifier $_{\text {in the }}$ reference population, there was no notable increase in accuracy of the index. In summary, the presence of ani-

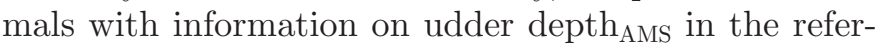
ence population was only of added value if the reference population contained a small number of animals with information on udder depth classifier $_{\text {. }}$

\section{DISCUSSION}

In this study, we performed a genetic analysis on udder conformation traits derived from teat coordinates recorded by AMS. We found that AMS udder conformation traits were genetically similar across parities and had a large repeatability within lactations. Moreover, they were genetically similar to corresponding udder conformation traits scored by classifiers, which is in agreement with Byskov et al. (2012) and Carlström et al. (2016b). Variance components could not be compared between udder conformation traits recorded by AMS and scored by classifiers, because of the difference in scale, but ratios of variance components, such as heritability, could be compared. The heritabilities of the AMS udder conformation traits were larger than the heritabilities of the corresponding traits scored by classifiers. This is in agreement with Byskov et al. (2012). However, the heritabilities estimated in this study were larger than in those of Byskov et al. (2012) and also Carlström et al. (2016b). This is probably due to differences in trait specification, analyzed AMS brand, and population. Weak to moderate genetic correlations existed between the AMS udder conformation traits and udder health, which were in agreement with Carlström et al. (2016a). The AMS udder conformation traits showed weak genetic correlations with longevity. Similar genetic correlations to udder health and longevity were found for rear teat distance recorded by AMS and for rear teat placement scored by classifiers. However, for udder depth and front teat placement, 
Table 7. Approximate genetic correlations ${ }^{1}$ between automatic milking system-based and classifier-based udder conformation traits and functional traits

\begin{tabular}{llrrrrr}
\hline & & \multicolumn{5}{c}{ Functional trait $^{3}$} \\
\cline { 3 - 7 } Item & $\begin{array}{l}\text { Conformation } \\
\text { trait }\end{array}$ & \multicolumn{1}{c}{ UH } & SCM & CM & SCS & LONG \\
\hline AMS & RTD & 0.06 & 0.11 & 0.01 & 0.15 & 0.02 \\
& FTD & -0.04 & -0.03 & -0.03 & -0.07 & -0.02 \\
& UD & 0.34 & 0.35 & 0.30 & 0.35 & 0.18 \\
& DFR & -0.23 & -0.24 & -0.20 & -0.27 & -0.17 \\
Classification & UB & -0.13 & -0.12 & -0.13 & -0.15 & -0.05 \\
& RTP & -0.02 & -0.10 & 0.00 & -0.10 & -0.05 \\
& FTP & 0.24 & 0.23 & 0.21 & 0.25 & 0.06 \\
& UD & 0.44 & 0.46 & 0.38 & 0.44 & 0.40 \\
\hline
\end{tabular}

${ }^{1}$ Approximate genetic correlations: Pearson correlations between breeding values, corrected for their reliabilities (Calo et al., 1973).

${ }^{2} \mathrm{RTD}=$ rear teat distance $\mathrm{FTD}=$ front teat distance; $\mathrm{UD}=$ udder depth; $\mathrm{DFR}=$ distance front-rear; $\mathrm{UB}=$ udder balance; RTP $=$ rear teat placement; FTP $=$ front teat placement.

${ }^{3} \mathrm{UH}=$ udder health; $\mathrm{SCM}=$ subclinical mastitis; $\mathrm{CM}=$ clinical mastitis; LONG = longevity.

the AMS-based trait had a weaker genetic correlation with the functional traits than the classifier-based trait. Therefore, udder conformation scored by classifiers seems to be a better indicator for udder health and longevity than udder conformation recorded by AMS.

\section{Development of Udder Conformation Over Time}

The genetic correlations of the AMS udder conformation traits between parities were close to unity, whereas the permanent environmental correlations between parities were considerably smaller. This shows that udder conformation changes over parities, but this change is mostly due to nongenetic factors. Because of the strong genetic correlations of the AMS udder conformation traits between parities, first-parity records are sufficient for estimating breeding values for udder conformation, and including udder conformation data from later parities by using indices would only marginally increase the accuracy of breeding values. The results of the univariate repeatability models showed that the repeatabilities of the AMS udder conformation traits within parities were large (between 0.89 and 0.97). This means that differences in udder conformation within an animal are considerably smaller than differences in udder conformation between animals. It also means that a single record on udder conformation per lactation is a good indicator of udder conformation in general. These results suggest that there is no need to change the current udder classification system, where udders are scored once in first parity by professional classifiers.

\section{A Future for AMS Udder Conformation Traits}

The question remains if there is any advantage of using AMS udder conformation traits in addition to, or instead of, the udder conformation traits scored by classifiers in breeding value estimation. The large

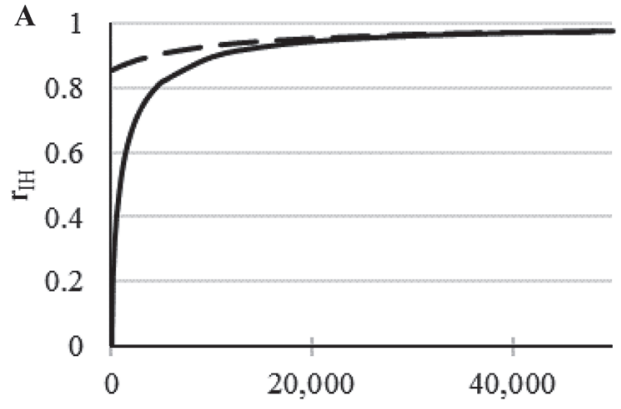

No. of cows with phenotype for classification score in reference population

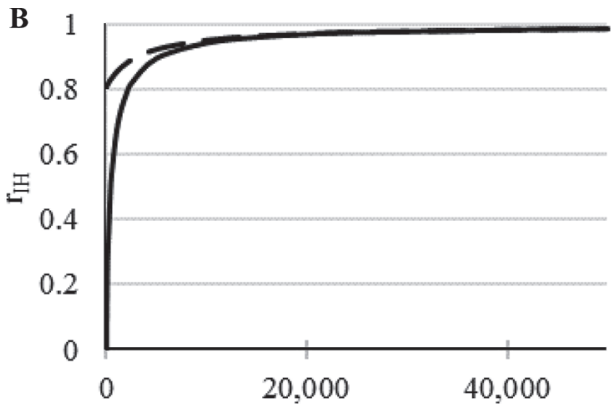

No. of bulls with breeding value for classification score in reference population

Figure 1. Accuracy of the genomic index for udder depth scored by classifiers $\left(\mathrm{r}_{\mathrm{IH}}\right)$ shown as a function of the number of animals in the reference population with information on udder depth scored by classifiers. Solid line: index consists only of the genomic breeding value for udder depth scored by classifiers. Dashed line: index consists of the genomic breeding value for udder depth scored by classifiers and the genomic breeding value for udder depth recorded by automatic milking systems (AMS; 15,000 cows or 5,000 bulls with information on udder depth recorded by AMS in reference population). $\mathrm{A}=$ reference population consisting of cows; $\mathrm{B}=$ reference population consisting of bulls. 
heritabilities of the AMS udder conformation traits compared with the classifier traits suggest that adding AMS info could increase the accuracy of breeding values for udder conformation. However, our selection index calculations showed that adding bulls with information on AMS udder conformation traits to a genomic reference population already containing $>15,000$ bulls with information on udder conformation traits scored by classifiers (as is the case in reality in Europe) results in a negligible increase in accuracy. Therefore, currently there is no benefit of including the AMS udder conformation traits in breeding value estimation in Europe, but AMS udder conformation traits could be of great value in countries without extensive classifier recording of conformation.

However, the question arises to what extent AMS udder conformation traits could replace classifier-based udder conformation traits. The strong genetic correlations (>0.91) between the AMS udder conformation traits and the corresponding traits scored by classifiers suggest that the 2 methods of measuring udder conformation result in traits that are determined largely by the same genes, and could be considered the same trait. Additionally, the selection index calculations showed that the accuracy of a genomic breeding value for udder depth scored by classifiers when only information on udder depth recorded by AMS is available is almost as large as the accuracy when only information on udder depth scored by classifiers is available. This implies that it would be possible to replace udder conformation traits scored by classifiers by AMS udder conformation traits.

However, for some udder conformation traits, the classifier-based version of the trait had a larger genetic correlation with udder health and longevity than the AMS-based version. Apparently, despite the strong genetic correlations between the AMS udder conformation traits and the classifier-based traits, there are some essential differences between the 2 traits that come to expression in their relation to longevity and udder health. An explanation for the larger genetic correlation between longevity and udder depth scored by classifiers than between longevity and udder depth recorded by AMS could be that there is an effect of stature on udder depth recorded by AMS. Udder depth recorded by AMS was defined as the distance from the floor to the teats. This distance may be in general larger for taller cows than for smaller cows, resulting in a shallower udder for taller cows than for smaller cows. Because the genetic correlation between stature and longevity is negative (Zavadilová and Štípková, 2012), the positive genetic correlation between udder depth recorded by AMS and longevity may be decreased. An explanation for the larger genetic correlation between udder health and front teat placement scored by classifiers than between udder health and front teat distance recorded by AMS could be that classifiers take into account the direction of the teats (pointing inward or outward) when scoring front teat placement, whereas AMS only record the location of the teat end. If this explanation is valid, our results indicate that not only the distance between front teats, but also the direction of the front teats is important for udder health. Thus, our results indicate that improvement of the definition and calculation of the AMS udder conformation traits is necessary before they can be used to replace udder conformation traits scored by classifiers.

\section{Additional Potential of Teat Coordinates}

Udder conformation traits as they are traditionally defined, both scored by classifiers and recorded by AMS, have limited value as indicators for udder health, longevity, and AMS efficiency. However, there might be more potential in AMS teat coordinates than we are aware of. For instance, temporary changes in udder depth and distance between teats may contain information about udder edema and clinical mastitis because both udder edema and clinical mastitis cause udders to swell (de Boyer des Roches et al., 2017; Morrison et al., 2018). Persistency within lactations could be analyzed using a random regression model, similar to what is used for milk production (CRV, 2012a). A random regression model would provide an estimated breeding value for each day in lactation and would allow for genetic changes within lactations. Moreover, there might be interactions between teat coordinate traits that might be better indicators of udder health, longevity, or AMS efficiency. Also, research about the use of imaging technologies for determining body conformation is ongoing (Fischer et al., 2015; Nir et al., 2017; Vlček et al., 2017). This could open up possibilities to automatically measure not only teat coordinates, but also other conformation traits, such as body height, BCS, and claw angle. Interactions between teat coordinates and other automatically recorded traits might give better reflections of functionality. A machine learning approach may be able to capture these interactions. Our study posed a start in exploring the use of AMS teat coordinate data, and more unique properties of this type of data are yet to be revealed.

\section{CONCLUSIONS}

This study showed that AMS-based udder conformation traits had strong genetic correlations between parities, indicating that udder conformation hardly changes genetically over parities. Moreover, repeatabilities of 
AMS-based udder conformation traits within parities were large. These results indicate that the current herd classification system, where udders are scored once in first parity, is sufficient for estimating breeding values for udder conformation. Including AMS-based udder conformation information would not increase the accuracy of breeding values for udder conformation considerably. Therefore, currently there is no benefit of AMS-based udder conformation traits. Moreover, some AMS-based udder conformation traits had considerably weaker genetic correlations with functional traits than the corresponding classifier-based traits. This shows that the methods to derive udder conformation traits from AMS teat records need fine-tuning before they could be considered to replace the classifier-based udder conformation traits.

\section{ACKNOWLEDGMENTS}

CRV is acknowledged for providing the data. Jorien Bouwmeester-Vosman (CRV BV, Arnhem, the Netherlands) is acknowledged for practical advice when analyzing the data.

\section{REFERENCES}

Byskov, K., L. H. Buch, and G. P. Aamand. 2012. Possibilities of implementing measures from automatic milking systems in routine evaluations of udder conformation and milking speed. Interbull Bull. 46:28-32.

Calo, L. L., R. E. McDowell, L. D. VanVleck, and P. D. Miller. 1973 Genetic aspects of beef production among Holstein Friesians pedigree selected for milk production. J. Anim. Sci. 37:676-682. https: //doi.org/10.2527/jas1973.373676x.

Carlström, C., E. Strandberg, K. Johansson, G. Pettersson, H. Stålhammar, and J. Philipsson. 2016a. Genetic associations of in-line recorded milkability traits and udder conformation with udder health. Acta Agric. Scand. A Anim. Sci. 66:84-91. https://doi.org/ 10.1080/09064702.2016.1260154.

Carlström, C., E. Strandberg, G. Pettersson, K. Johansson, H. Stålhammar, and J. Philipsson. 2016b. Genetic associations of teat cup attachment failures, incomplete milkings, and handling time in automatic milking systems with milkability, temperament, and udder conformation. Acta Agric. Scand. A Anim. Sci. 66:75-83. https://doi.org/10.1080/09064702.2016.1260153.

CRV. 2012a. E-7 Breeding value estimation of milk production traits with test-day model. Accessed Feb. 14, 2018. https://www .crv4all-international.com/wp-content/uploads/2016/03/E-7-milk -production.pdf.

CRV. 2012b. E-19 Breeding value for longevity. Accessed Feb. 14, 2018. https:// www.crv4all-international.com/wp-content/uploads/ 2016/03/E-19-Longevity.pdf.

CRV. 2016a. E-8 Breeding value estimation for conformation traits. Accessed Feb. 14, 2018. https://www.crv4all-international.com/ wp-content/uploads/2016/04/E_08_ext_eng.pdf.

CRV. 2016b. E-27 Breeding value udder health. Accessed Feb. 14, 2018. https://www.crv4all-international.com/wp-content/uploads 2016/04/E_27_apr2016_eng.pdf.

CRV. 2018a. E-20 NVI. Accessed Aug. 8, 2018. https://www.crv4all -international.com/wp-content/uploads/2018/06/E_20-NVI _apr2018_en.pdf.

CRV. 2018b. Holstein. Accessed May 30, 2018. https://www.crv4all .nl/service/holstein/.
Daetwyler, H. D., B. Villanueva, and J. A. Woolliams. 2008. Accuracy of predicting the genetic risk of disease using a genome-wide approach. PLoS One 3:e3395. https://doi.org/10.1371/journal.pone .0003395 .

de Boyer des Roches, A., M. Faure, A. Lussert, V. Herry, P. Rainard, D. Durand, and G. Foucras. 2017. Behavioral and patho-physiological response as possible signs of pain in dairy cows during Escherichia coli mastitis: A pilot study. J. Dairy Sci. 100:8385-8397. https://doi.org/10.3168/jds.2017-12796.

Dekkers, J. C. M. 2007. Prediction of response to marker-assisted and genomic selection using selection index theory. J. Anim. Breed. Genet. 124:331-341. https://doi.org/10.1111/j.1439-0388.2007 .00701.x.

Elgersma, G. G., G. de Jong, R. van der Linde, and H. A. Mulder. 2018. Fluctuations in milk yield are heritable and can be used as a resilience indicator to breed healthy cows. J. Dairy Sci. 101:12401250. https://doi.org/10.3168/jds.2017-13270.

Fischer, A., T. Luginbühl, L. Delattre, J. M. Delouard, and P. Faverdin. 2015. Rear shape in 3 dimensions summarized by principal component analysis is a good predictor of body condition score in Holstein dairy cows. J. Dairy Sci. 98:4465-4476. https://doi.org/ 10.3168/jds.2014-8969.

Gilmour, A. R., B. J. Gogel, B. R. Cullis, S. J. Welham, and R. Thompson. 2015. ASReml User Guide Release 4.1. VSN International Ltd., Hemel Hempstead, UK.

Larroque, H., R. Rupp, S. Moureaux, D. Boichard, and V. Ducrocq. 1999. Genetic parameters for type and functional traits in the French Holstein breed. Interbull Bull. 23:169-179.

Lee, S. H., S. Clark, and J. H. J. van der Werf. 2017. Estimation of genomic prediction accuracy from reference populations with varying degrees of relationship. PLoS One 12:e0189775. https://doi.org/10 .1371/journal.pone.0189775.

Morrison, E. I., T. J. DeVries, and S. J. LeBlanc. 2018. Short communication: Associations of udder edema with health, milk yield, and reproduction in dairy cows in early lactation. J. Dairy Sci. 101:9521-9526. https://doi.org/10.3168/jds.2018-14539.

Nir, O., Y. Parmet, D. Werner, G. Adin, and I. Halachmi. 2017. 3D Computer-vision system for automatically estimating heifer height and body mass. Biosyst. Eng. 173:4-10. https://doi.org/10.1016/j .biosystemseng.2017.11.014.

Rupp, R., and D. Boichard. 1999. Genetic parameters for clinical mastitis, somatic cell score, production, udder type traits, and milking ease in first lactation Holsteins. J. Dairy Sci. 82:2198-2204. https: //doi.org/10.3168/jds.S0022-0302(99)75465-2.

Rutten, M. J. M., P. Bijma, J. A. Woolliams, and J. A. M. Van Arendonk. 2002. SelAction: Software to predict selection response and rate of inbreeding in livestock breeding programs. J. Hered. 93:456-458. https://doi.org/10.1093/jhered/93.6.456.

Samoré, A. B., and A. F. Groen. 2006. Proposal of an udder health genetic index for the Italian Holstein Friesian based on first lactation data. Ital. J. Anim. Sci. 5:359-370. https://doi.org/10.4081/ ijas.2006.359.

Short, T. H., and T. J. Lawlor. 1992. Genetic parameters of conformation traits, milk yield, and herd life in Holsteins. J. Dairy Sci. 75:1987-1998. https://doi.org/10.3168/jds.S0022-0302(92)77958 -2 .

Stichting Kwaliteitszorg Onderhoud Melkinstallaties. 2018. Statistiek. Accessed May 30, 2018. http://www.stichtingkom.nl/index.php/ stichting_kom/category/statistiek.

Vlček, M., J. Tomka, and R. Kasarda. 2017. Evaluation of claw conformation by using two methods of measuring-by ruler and image analysis. ACS Agric. Conspec. Sci. 82:193-196.

Vollema, A. R., S. Van Der Beek, A. G. F. Harbers, and G. De Jong. 2000. Genetic evaluation for longevity of Dutch dairy bulls. J. Dairy Sci. 83:2629-2639. https://doi.org/10.3168/jds.S0022 -0302(00)75156-3.

Zavadilová, L., and M. Štípková. 2012. Genetic correlations between longevity and conformation traits in the Czech Holstein population. Czech J. Anim. Sci. 57:125-136. https://doi.org/10.17221/ 5566-CJAS. 